\title{
Goaf Compaction Evaluation Based on Integrity and Permeability Measurement of the Overburden Strata
}

\author{
Xiaorong ZHAI, Guangtao WANG, Jiwen WU, Yaoshan BI
}

\begin{abstract}
Groundwater outbursts from coal mine goafs, which are widely distributed in China with the increase in the number of abandoned coal mines, demonstrate an impartible relationship with the permeability of goaf overburden strata. A research on rock mass integrity and permeability characteristics of goaf overburden strata is necessary to assess waterinrush risk induced by goaf water. Two goafs in two adjacent coal mines located at the Huaibei mining area in the Anhui Province of China were considered as the research targets. A ground exploration hole was conducted in each goaf. The rock mass integrity and fracture development of goaf overburden strata were determined on the basis of rock quality designation (RQD) and borehole television. The permeability of goaf overburden strata was measured by performing a field packer test. Results are as follows: (1) The fracture development of the borehole wall of the production mine is favorable, and a water drenching phenomenon occurs. The RQD is approximately $20.8-35.6 \%$, which indicates that the integrity of the goaf overburden strata of the production mine is poor. The unit water inflow $(q)$ is $0.133 \mathrm{~L} / \mathrm{s} . \mathrm{m}$, and the average permeability coefficient is $0.26 \mathrm{~m} / \mathrm{d}$, which reveals that the goaf overburden strata of the production mine exhibit medium water abundance and permeable strata. (2) The overburden strata parameters of the abandoned mine goaf are as follows: the $q$ is $0.012-0.014 \mathrm{~L} / \mathrm{s}$.m, and the average permeability coefficient is $0.005 \mathrm{~m} / \mathrm{d}$, which suggests that the goaf overburden strata exhibit poor water abundance and low permeable strata. The results demonstrate that the overburden strata compaction of the two goafs is different and the results can provide a reference for adjacent mines to access the water inrush risk induced by the goaf water of the abandoned coal mines.
\end{abstract}

Keywords: overburden strata; packer test; permeability coefficient; water inrush

\section{INTRODUCTION}

Mine water disaster has constantly been a major catastrophe that threatens the safety of coal mine production in China $[1 \div 3]$. Coal mining in China went through a rapid development stage. The number of abandoned coal mines increases with the adjustment of energy structure and the implementation of a national capacity to implement policies. The demands for safe and efficient exploitation of coal resources are also increasing. China has been faced with a severe problem of coal resources exhaustion. According to the statistics, nearly one-third of large- and medium-scale coal mines reach or are near the design years, and the proportion accounts for $56.52 \%$ [4]. Groundwater cannot be pumped after closing the coal mines, thereby causing serious security threats to adjacent production mines. Many serious and severe water

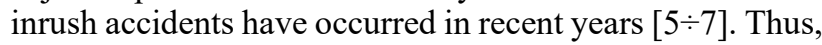
the integrity and permeability of goaf overburden strata are crucial for water resistance in adjacent abandoned coal mines. In addition, integrity and permeability are common scientific problems for coal pillar retention and gas extraction $[8 \div 10]$.

However, the existing research results on goaf water hazards induced by abandoned coal mines have been mainly focused on the dynamic recovery process of goaf water level $[11 \div 13]$, environmental pollution induced by groundwater recharge [14] and stability evaluation of coal pillar [15]. The integrity and permeability change induced by goaf overburden strata compaction have not been considered. The goaf can be re-compacted under the geostatic pressure of overlying strata with time. The direct threat to the adjacent production mines is the rising of the goaf water level. The key to determine the rising rate of the goaf water level and the regenerative water-resisting ability of the fillings in the goaf is the integrity and permeability of the overburden strata. Thus, it is necessary to study the integrity and permeability of goaf overburden strata.

In order to scientifically evaluate the threat of goaf water to adjacent production mines, it is necessary to evaluate the goaf overburden strata compaction degree on both sides of the mining boundary. Considering the limitations of simple theoretical calculation and simulation, a field test method is proposed in this study to evaluate the integrity and permeability of the goaf overburden strata, and the compaction of the goaf overburden strata is studied.

\section{STATE OF THE ART}

Scholars all over the world have conducted plenty of relevant studies on the integrity and permeability of the goaf overburden strata. Brett et al. [16] estimated the permeability change of overburden strata during longwall mining by PFC2D software. The permeability coefficient and porosity metrics were calculated and the height of the enhanced permeability fractured zone above a longwall goaf was identified. The results showed that the permeability coefficient increased approximately eight orders-of-magnitude in the caved zone and one to two orders-of-magnitude in the strata above the fractured zone. Bai et al. [17] described the stress-strain relationship of caved rock, thus verifying the compaction theory of goaf on the basis of the FLAC3D software and this theory was successfully applied in practice. Meng et al. [18] discussed the relationship between permeability and the stress of goaf rock mass based on the deformation and failure characteristics of goaf overburden strata and achieved the transverse and longitudinal zoning of goaf. Adhikaryand Guo [19] investigated the strata permeability change induced by longwall mining at a mine site in New South Wales on the basis of an underground packer test and numerical simulation. These authors concluded that the permeability of goaf overburden strata increased more than 1000 -fold and measured permeability coefficient varied widely and remarkably in different positions. Schatzel et al. [20] studied the permeability change in goaf overburden strata induced by coal mining by a field measurement method. These researchers concluded that the permeability of the overburden strata increased by hundred to thousand times, and the permeability continuously changed 7 months after coal mining. Qureshi et al. [21] calculated the rock quality designation (RQD) based on core drilling. The 
empirical relationship between permeability coefficient and RQD of unconsolidated sedimentary rocks in Oman area was established. The results were consistent with those obtained by a field packer test, thus revealing the relationship between RQD and permeability coefficient of the rock mass. Song et al. [22] established the permeability coefficient calculation model for fracture rock mass based on the RQD and the distribution characteristics of permeability coefficient of water sealed underground storage caverns in Qingdao were obtained. Vincenzo et al. [23] conducted a field packer test in hard rocks (mainly andesites and metamorphites of western Turkey) and the relationship between permeability coefficient and depth of hard rocks was obtained. The results showed that the permeability coefficient decreased with the increase of depth and there was no obvious relationship between RQD and rock burial depth. Xue et al. [24] established the fracture distribution model from the gas extraction point of review by a similar material simulation test and the conditions for the rapid change of gas migration were obtained. Lu et al. [25] established a mining model above a confined aquifer using a numerical simulation method. The permeability change law of coal floor was achieved during coal mining based on the fluid-solid coupling theory. They concluded that a higher homogeneity index of floor strata could result in a sudden formation of water inrush. In order to evaluate the influence of coal seam mining on surface water system, Khanal et al. [26] investigated the change in permeability on the overburden strata due to the longwall mining by a numerical simulation method. These researchers concluded that the permeability of the overburden strata increased in excess of six orders of magnitude and the permeability change varied with different mining methods. Holla et al. [27] investigated the coal roof cracking and surface deformation during mining in a shallow longwall working face. Meanwhile, the permeability of overburden strata was measured by the packer test. The results concluded that the height of fracture zone in a shallow working face was 9 times the thickness of the coal seam, and the RQD had a good correlation with permeability. Guo et al. [28] used the numerical simulation method to comprehensively study the law of surface movement, fracture development and gas migration during mining in a deep longwall working face in Anhui Province, China. The stress evolution in overburden strata, fracture development and gas migration law were obtained, and the best gas drainage area around the longwall working face was determined, thus providing a support for gas extraction. Zhang et al. [29] used FLAC3D software to analyze the mining induced fracture and stress evolution in overburden strata of a longwall working face, and they obtained that the coal roof could be divided into five zones. The gas migration area was determined to provide a basis for eliminating gas outburst. Chen et al. [30] calculated the mining induced permeability change by a numerical simulation method based on the Biot theory, and the water inrush risk from an aquifer above the coal seam was predicted. The results showed that the mining induced permeability change was exponentially related to the aquifer water pressure change, which was consistent with the field test results.

Current research mainly includes the following subjects: the permeability investigation of overburden strata by numerical simulation and similar material simulation for revealing the gas migration law [24, 28, 29]; the surface water protection and the prediction of water inrush risk from coal seam roof or coal floor by numerical simulation $[25,26,30]$; the research of permeability change law in overburden strata by a numerical simulation method simply [16 $\div 18]$. Some other scholars have carried out the permeability measurement of overburden strata by the field test, but they have mainly studied the evolution law of permeability with time and space, without considering the water-resisting ability of the goaf $[21,22$, 27]. In summary, there have been many studies on the integrity and permeability of overburden strata, but minimal consideration is related to the goaf overburden strata compaction.

In order to reveal the goaf overburden strata compaction degree and avoid the limitations of numerical simulation and similar material simulation methods, the integrity and permeability of goaf overburden strata in the Huaibei mining area of China are studied on the basis of RQD index, borehole television, and packer tests. The results can provide a new method for evaluating the goaf overburden strata compaction in the abandoned coal mines.

The remainder of this study is organized as follows. Section 3 elaborates the basic geological survey and research methods adopted in the study area. Section 4 evaluates the goaf overburden strata compaction degree based on the results of RQD and permeability coefficient. Section 5 summarizes and concludes the study.

\section{METHODOLOGY 3.1 Geological Settings}

The Huaibei mining area, which is located in Northern Anhui Province, is a major mining area in Eastern China (Fig. 1). The target coal mine goafs are located in Yuanzhuang and Shenzhuang coal mines of the Huaibei mining area. Stratigraphic classification of the study area belongs to the North China-type strata, and the primary mineable coal seam is the No. 3 coal seam, which is located in the Lower Permian Shihezi formation.

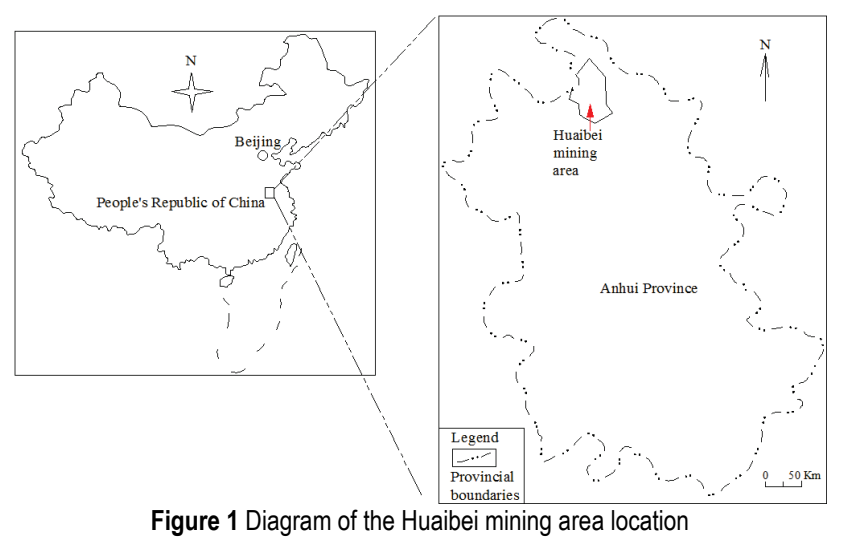

The general structural feature of the area is a monoclinal structure with NE trend and a dip angle of 20 $30^{\circ}$. The Shenzhuang coal mine is an abandoned mine and the underground water is not pumped any more, whereas the Yuanzhuang coal mine is a production mine. The boundary of the two mines is an artificial boundary, that is, the boundary is a coal pillar boundary. Therefore, the production of the Yuanzhuang mine is threatened by the goaf water in the Shenzhuang mine. The study of the integrity and permeability of the goaf overburden strata 
near the coal mine boundary is necessary to provide a reference for the goaf waterinrush evaluation of the Yuanzhuang coal mine.

The two nearest working faces of the two adjacent mines are working face III3142 mined in 1993-1994 of the Yuanzhuang coal mine and working face S2II313 mined in 1973 of the Shenzhuang coal mine (Fig. 2). The minimum distance between the two working faces is less than $20 \mathrm{~m}$, and working face S2II313 is located in the shallow part of working face III3142. The working face III3142 goaf is connected with the main roadways in the mine. Therefore, the goaf water of working face S2II313 may flow into the Yuanzhuang coal mine through the fracture zone of the goaf overburden strata between the two adjacent working faces.

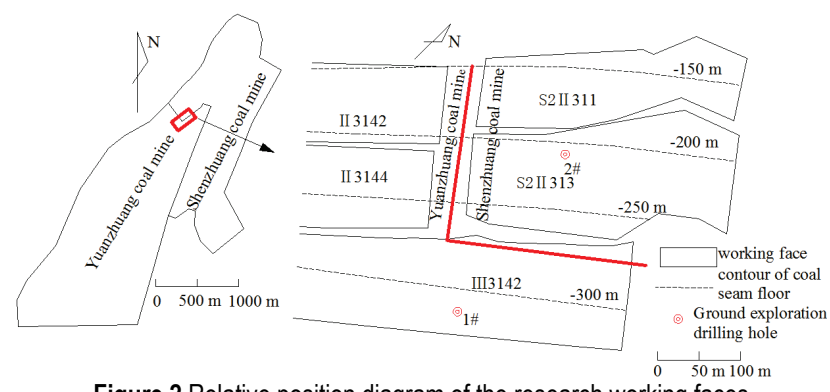

Figure 2 Relative position diagram of the research working faces

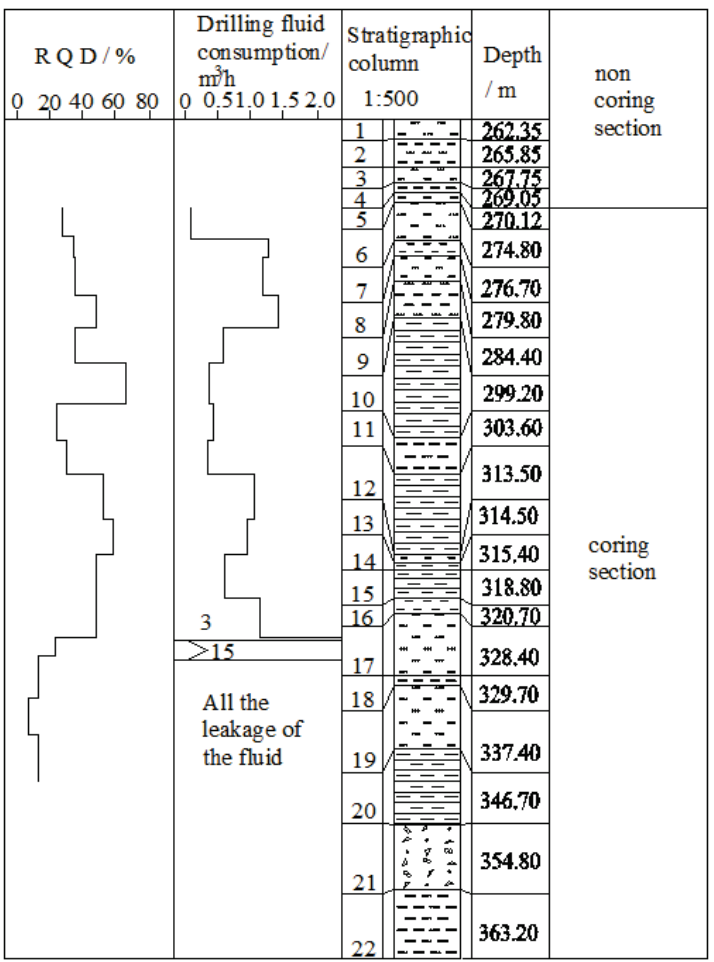

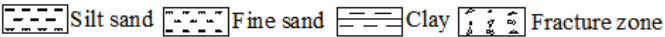
Figure 3 Stratigraphic column of the No. 1 hole

\subsection{Drilling Exploration}

Two ground holes (marked as $1 \#$ and 2\#) were conducted by drilling to investigate the integrity and permeability of the goaf overburden strata. The No. 1 hole is located in working face III3142, and No. 2 hole is found in working face S2II313 (Fig. 2). The average thickness of quaternary strata is $43,35 \mathrm{~m}$. The depth of No. 1 hole is $363.20 \mathrm{~m}$, and the depth from 43.35 to $270.12 \mathrm{~m}$ is the non- coring section. The rocks mainly comprise mudstone, siltstone, and fine sandstone based on logging data. The depth from 270.12 to $363.20 \mathrm{~m}$ is the coring section, and the lithology and thickness are $35.08 \mathrm{~m}$ mudstone, $13.16 \mathrm{~m}$ fine sandstone, and $22.62 \mathrm{~m}$ sandstone (Fig. 3). The thickness of the caving fracture zone is approximately 8.10 $\mathrm{m}$, the cores are cracked and loosened, and the high-angle fractures are developed (Fig. 4). The depth of No. 2 hole is $280.67 \mathrm{~m}$ and is a non-coring hole. The rocks also mainly comprise mudstone, siltstone, and fine sandstone based on logging data.

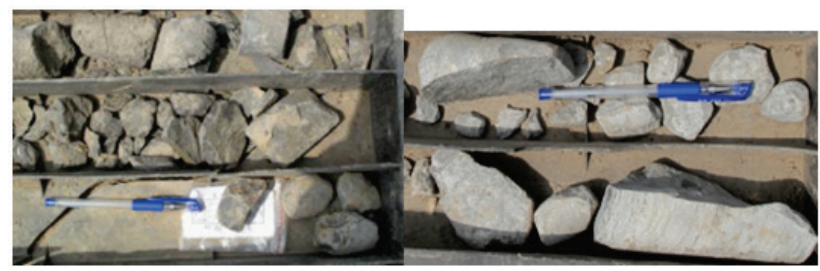

Figure 4 Cores of the goaf caving zone of No. 1 hole

\subsection{Borehole Television Exploration}

Borehole television images were used to identify and determine the characteristics of an in-depth fracture development [31]. Therefore, this method was used to investigate the fracture development characteristics of the No. 1 hole. The borehole television images are displayed in Fig. 5. Borehole television is not conducted in No. 2 hole induced by the collapsed hole.

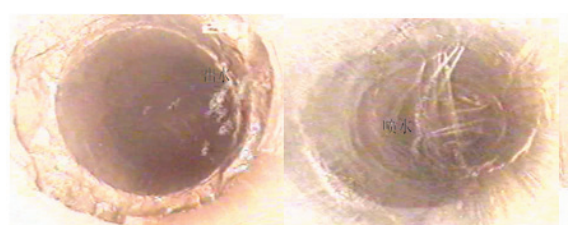

(a)

(d)

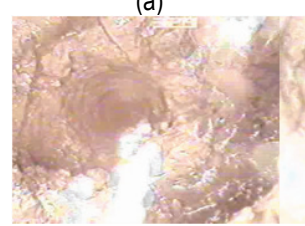

(b)

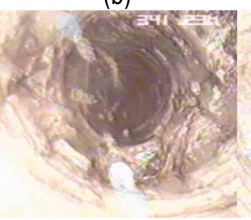

(e)

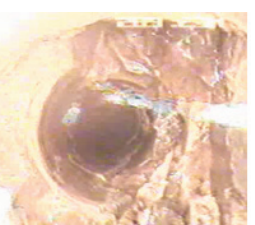

(c)
Figure 5 (a) Water effluent in depth of $287 \mathrm{~m}$. (b) Water spray in depth of $285 \mathrm{~m}$. (c) Water spray in depth of $289 \mathrm{~m}$. (d) Fractures developed in depth of $329 \mathrm{~m}$. (e) Fractures developed in depth of $341 \mathrm{~m}$. (f) Water surface in depth of $361 \mathrm{~m}$

\subsection{Packer Test}

Packer test is a common method for testing the permeability of rock mass in engineering [32]. In this study, the packer tests were conducted in two boreholes drilled vertically from the surface. The equipment utilized in this study is illustrated in Fig. 6. Fig. 2 displays the location of the test site. A standard packer test was conducted in No. 2 hole, and a simple packer test was conducted in No. 1 hole. 


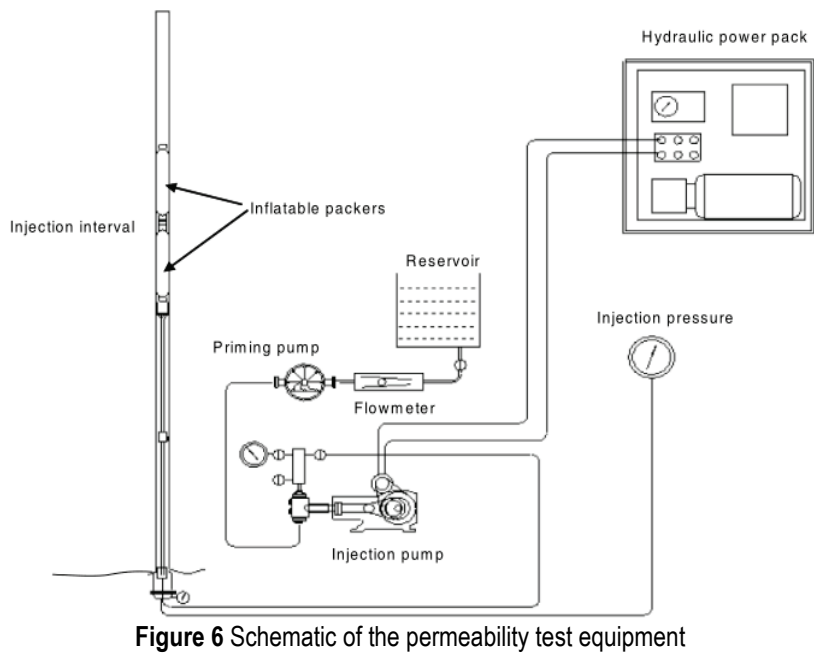

\subsubsection{Packer Test in No. 2 Hole}

The hole was thoroughly washed before the packer test until the water was clear in the hole. The duration for stabilizing injection water was more than $24 \mathrm{~h}$, and the change range of water level and injection rate was 0 . Finally, the recovery water level was observed, and the cement slurry was blocked after the test. The process and results of the packer test are presented in Tab. 1 and Fig. 7, respectively.

Table 1 Observation records of the packer test process

\begin{tabular}{|c|c|c|c|c|}
\hline \multirow{2}{*}{ Time } & \multicolumn{2}{|c|}{ Water injection rate } & \multicolumn{2}{c|}{ Water level / m } \\
\cline { 2 - 5 } & $(\mathrm{L} / \mathrm{s})$ & $\left(\mathrm{m}^{3} / \mathrm{h}\right)$ & Elevation & Uplift height \\
\hline $0: 30$ & 3,04 & 10,93 & $-160,61$ & 0,07 \\
\hline $0: 31$ & 3,04 & 10,93 & $-131,96$ & 28,65 \\
\hline $0: 35$ & 3,04 & 10,93 & $-17,36$ & 143,25 \\
\hline $0: 44$ & 3,04 & 10,93 & 35,70 & 196,31 \\
\hline $1: 00$ & 1,13 & 4,07 & 35,70 & 196,31 \\
\hline $2: 00$ & 1,13 & 4,07 & 35,70 & 196,31 \\
\hline $3: 00$ & 1,13 & 4,07 & 35,70 & 196,31 \\
\hline $4: 00$ & 1,13 & 4,07 & 35,70 & 196,31 \\
\hline $6: 00$ & 1,13 & 4,07 & 35,70 & 196,31 \\
\hline $8: 00$ & 1,13 & 4,07 & 35,70 & 196,31 \\
\hline $10: 00$ & 1,13 & 4,07 & 35,70 & 196,31 \\
\hline $12: 00$ & 1,13 & 4,07 & 35,70 & 196,31 \\
\hline $16: 00$ & 1,13 & 4,07 & 35,70 & 196,31 \\
\hline $20: 00$ & 1,13 & 4,07 & 35,70 & 196,31 \\
\hline $24: 00$ & 1,13 & 4,07 & 35,70 & 196,31 \\
\hline
\end{tabular}

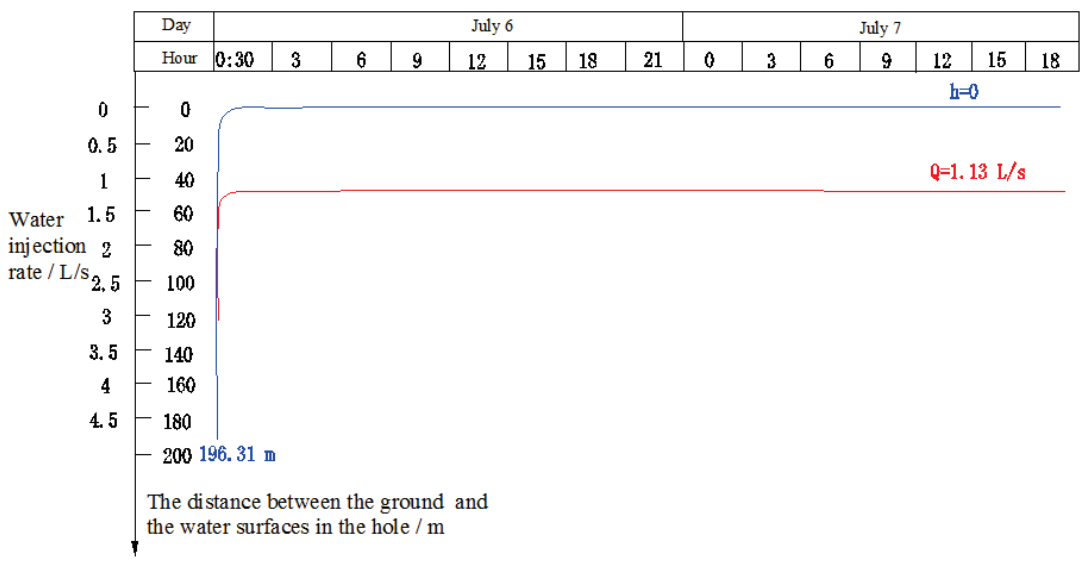

(a)

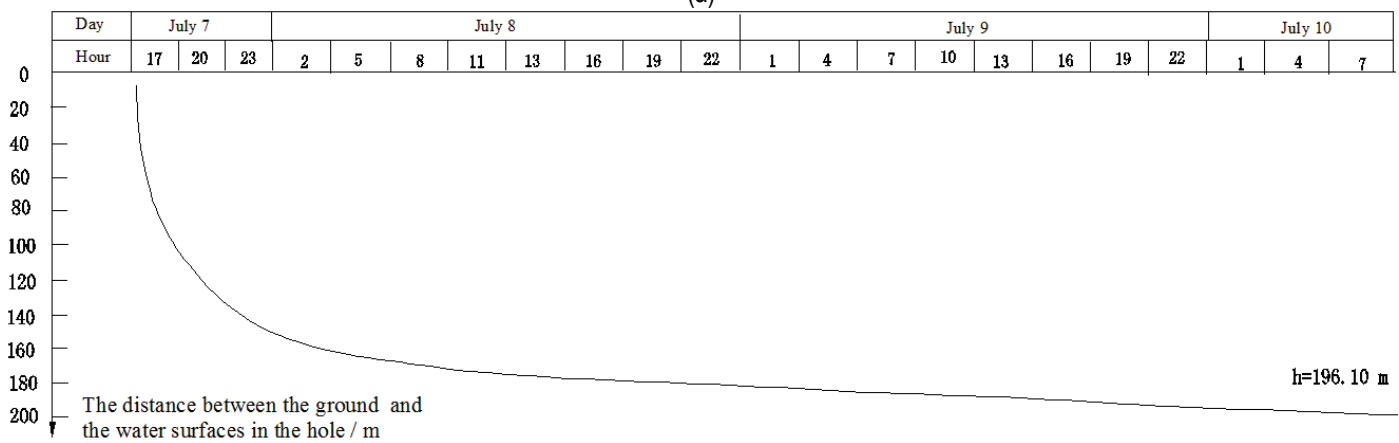

(b)

Figure 7(a) Water level versus time and (b) recovery curve of the water leve

The permeability coefficient is calculated by the Dupuit and Babushkin formulas based on test data.

(1) The Dupuit formula is as follows:

$K=0.366 \frac{Q}{M S} \lg \frac{R}{r}, R=10 S \sqrt{K}$,

where $Q$ is the injection water flow $(\mathrm{L} / \mathrm{s}) ; M$ is the injection interval (m); $S$ is the uplift height of the water level (m); $R$ is the influence radius $(\mathrm{m}) ; r$ is the borehole radius (m); and $K$ is the permeability coefficient $(\mathrm{m} / \mathrm{d})$.
The packer test in No. 2 hole was divided into three sections. The injection intervals are $41.38,84.23$, and 36.84 $\mathrm{m}$, the uplift height of the water level is $196.31 \mathrm{~m}$, and the borehole radius is $0.0455 \mathrm{~m}$. The data are inputted into formula (1), and the calculation results are listed in Tab. 2.

Table 2 Results of the packer test using the Dupuit formula

\begin{tabular}{|c|c|c|c|c|c|}
\hline$M / \mathrm{m}$ & $S / \mathrm{m}$ & $Q / \mathrm{L} / \mathrm{s}$ & $q / \mathrm{L} / \mathrm{s} . \mathrm{m}$ & $K / \mathrm{m} / \mathrm{d}$ & $R / \mathrm{m}$ \\
\hline 41,38 & 196,31 & 1,13 & 0,00576 & 0,016 & 250 \\
\hline 84,23 & 196,31 & 1,13 & 0,00576 & 0,007 & 165 \\
\hline 36,84 & 196,31 & 1,13 & 0,00576 & 0,019 & 270 \\
\hline
\end{tabular}


The permeability varies in different sections. The average permeability coefficient is calculated as $0.014 \mathrm{~m} / \mathrm{d}$, and the unit water inflow $(q)$ is $0.00576 \mathrm{~L} / \mathrm{s} . \mathrm{m}$.

(2) The Babushkin formula is as follows:

$K=0.528 \omega \lg \left(\frac{1.32 L}{r}\right)$

where $K$ is the permeability coefficient $(\mathrm{m} / \mathrm{d}) ; \omega$ is the unit water absorption (L/min.m.m); $L$ is the injection interval $(\mathrm{m})$; and $r$ is the borehole radius $(\mathrm{m})$. The unit water absorption is calculated by the formula as follows:

$\omega=\frac{Q}{L P}$

where $L$ is the injection interval (m); and $P$ is the water pressure using a water head express (m).

The data are inputted to formulas (2) and (3), and the calculation results are shown in Tab. 3 .

Table 3 Results of the packer test using the Babushkin formula

\begin{tabular}{|c|c|c|c|c|c|}
\hline$L / \mathrm{m}$ & $P / \mathrm{m}$ & $\begin{array}{c}\text { Recovery } \\
\text { water } \\
\text { level } / \mathrm{m}\end{array}$ & $\begin{array}{c}Q / \\
\mathrm{L} / \mathrm{s}\end{array}$ & $\begin{array}{c}\omega / \\
\mathrm{L} / \mathrm{min} . \mathrm{m} \cdot \mathrm{m}\end{array}$ & $K / \mathrm{m} / \mathrm{d}$ \\
\hline 41,38 & 196,31 & 196,10 & 1,13 & 0,0083 & 0,014 \\
\hline 84,23 & 196,31 & 196,10 & 1,13 & 0,0041 & 0,007 \\
\hline 36,84 & 196,31 & 196,10 & 1,13 & 0,0094 & 0,015 \\
\hline
\end{tabular}

The average permeability coefficient is calculated as $0.012 \mathrm{~m} / \mathrm{d}$, and the unit water absorption is 0.0073 L/min.m.m.

\subsubsection{Packer Test in No. 1 Hole}

The packer test in No. 1 hole was a simple test. Drilling fluid was consumed when the depth was $270.12 \mathrm{~m}$, and fluid consumption was serious when the depth was 323.65 $\mathrm{m}$. The injection interval was from 270.12 to $323.65 \mathrm{~m}$. The distance between the ground and the water surface in the hole was $110.90 \mathrm{~m}$. The packer test was then conducted. The water injection rate was $15000 \mathrm{l} / \mathrm{s}$ for $1 \mathrm{~h}$, and the distance between the ground and the water surface in the hole became stable at $79.60 \mathrm{~m}$. Then, the groundwater depth which fluctuated from 88.50 to $96.25 \mathrm{~m}$ was observed. The permeability coefficient is calculated by the Dupuit and Babushkin formulas, as expressed in formulas (1) - (3) based on the test data.

The injection interval is $53.53 \mathrm{~m}$, and the uplift height of the water level is $31.30 \mathrm{~m}$, and the borehole radius is $0.0455 \mathrm{~m}$. The data are inputted into formula (1). The permeability coefficient is calculated as $0.28 \mathrm{~m} / \mathrm{d}$, and the $q$ is $0.133 \mathrm{~L} / \mathrm{s} . \mathrm{m}$. The data are inputted into formulas (2) and (3). The permeability coefficient is calculated as 0.25 $\mathrm{m} / \mathrm{d}$, and the unit water absorption is $0.15 \mathrm{~L} / \mathrm{min} . \mathrm{m} . \mathrm{m}$.

\section{RESULT ANALYSIS AND DISCUSSION \\ 4.1 Integrity of the Goaf Overburden Strata}

The rock mass integrity is closely related to the fracture development degree. The RQD is a quantitative parameter that reflects the integrity of rock mass. The RQD was proposed by Deere [33] as a measure of the quality of borehole core and was defined as the percentage of borehole core or scanline that consisted of intact lengths $\geq 0.1 \mathrm{~m}$, and hence, it can be defined as follows:

$R Q D=100 \sum_{i=1}^{n} \frac{l_{i}}{L}$,

where $l_{\mathrm{i}}$ is the length of the $i^{\text {th }}$ intact length $\geq 0.1 \mathrm{~m}, n$ is the number of intact lengths $\geq 0.1 \mathrm{~m}$, and $L$ is the total length of the borehole core or scanline. Moreover, the RQD is the most easily obtained index in the exploration work. Thus, it is widely applied in engineering [34, 35]. The RQD of No. 1 hole is calculated on the basis of the cores and compared with the extraction rate of cores (Tab. 4 and Fig. 8).

Table $4 \mathrm{RQD}$ of the No. 1 hole coring section

\begin{tabular}{|c|c|c|c|c|c|}
\hline Depth /m & $\begin{array}{c}\text { Drilling } \\
\text { footage } \\
/ \mathrm{m}\end{array}$ & $\begin{array}{c}\text { Core } \\
\text { length } \\
/ \mathrm{m}\end{array}$ & $\begin{array}{c}\text { Cumulative core } \\
\text { length of more } \\
\text { than } 10 \mathrm{~cm} / \mathrm{m}\end{array}$ & $\begin{array}{c}\text { Core } \\
\text { extraction } \\
\text { rate } / \%\end{array}$ & $\begin{array}{c}\text { RQD } \\
/ \%\end{array}$ \\
\hline $\begin{array}{c}270,13- \\
274,32\end{array}$ & 4,20 & 2,60 & 1,19 & 61,9 & 28,3 \\
\hline $\begin{array}{c}274,32- \\
276,90\end{array}$ & 2,58 & 1,60 & 0,90 & 62,0 & 34,9 \\
\hline $\begin{array}{c}276,90- \\
281,54\end{array}$ & 4,64 & 4,00 & 1,65 & 86,2 & 35,6 \\
\hline $\begin{array}{c}281,54- \\
285,64\end{array}$ & 4,10 & 4,00 & 1,98 & 97,6 & 48,3 \\
\hline $\begin{array}{c}285,64- \\
289,90\end{array}$ & 4,62 & 3,50 & 1,63 & 75,8 & 35,3 \\
\hline $\begin{array}{c}289,90- \\
294,89\end{array}$ & 4,99 & 4,99 & 3,33 & 100,0 & 66,7 \\
\hline $\begin{array}{c}294,89- \\
299,39\end{array}$ & 4,50 & 3,50 & 1,09 & 77,8 & 24,2 \\
\hline $\begin{array}{c}299,39- \\
303,69\end{array}$ & 4,30 & 4,30 & 1,30 & 100,0 & 30,2 \\
\hline $\begin{array}{c}303,69- \\
309,20\end{array}$ & 5,51 & 5,10 & 2,90 & 92,6 & 52,6 \\
\hline $\begin{array}{c}309,20- \\
313,58\end{array}$ & 4,38 & 4,30 & 2,57 & 98,2 & 58,7 \\
\hline $\begin{array}{c}313,58- \\
318,91\end{array}$ & 5,33 & 5,00 & 2,61 & 93,8 & 49,0 \\
\hline $\begin{array}{c}318,91- \\
323,65\end{array}$ & 4,74 & 4,00 & 2,32 & 84,4 & 48,9 \\
\hline $\begin{array}{c}323,65- \\
326,05\end{array}$ & 2,40 & 1,40 & 0,57 & 58,3 & 23,8 \\
\hline $\begin{array}{c}326,05- \\
331,18\end{array}$ & 5,13 & 2,50 & 0,68 & 48,7 & 13,3 \\
\hline $\begin{array}{c}331,18- \\
335,70\end{array}$ & 4,52 & 2,00 & 0,33 & 44,2 & 7,3 \\
\hline $\begin{array}{c}335,70- \\
341,34\end{array}$ & 4,64 & 2,60 & 0,60 & 56,0 & 12,9 \\
\hline
\end{tabular}

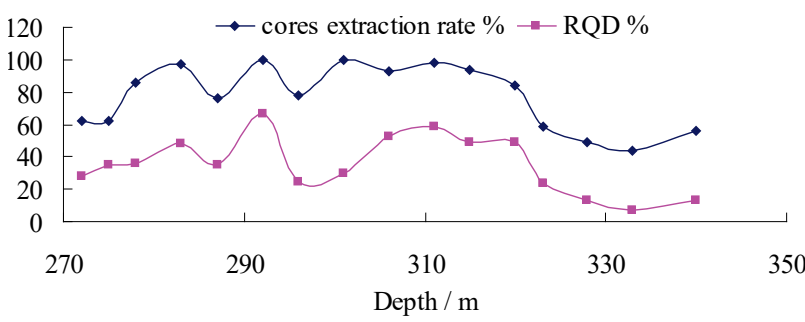

Figure 8 Relationship between the cores extraction rate and RQD of No. 1 hole

The RQD of the No. 1 hole core ranged from 7.3 to $66.7 \%$, and the average value was $35.6 \%$, which revealed that the integrity of the overburden strata of working face III3142 was poor, and the fractures developed well. In addition, a favorable correlation was found between the core adoption rate and the RQD, and the RQD value was 
small in the section of a high drilling fluid consumption (Fig. 3).

The borehole television results showed that the fractures developed well in the overburden strata of working face III3142 (Fig. 5). The distance between the ground and water surface in the hole was approximately $350.8 \mathrm{~m}$, and the depth of goaf water in the hole was approximately $1.1 \mathrm{~m}$. Water effluent phenomenon was evident on the hole wall, thus demonstrating that the integrity of working face III3142 goaf overburden strata was poor.

\subsection{Permeability of the Goaf Overburden Strata}

The packer test on No. 2 hole indicated that the results obtained by the two methods were similar. The $q$ was $0.00576 \mathrm{~L} / \mathrm{s} . \mathrm{m}$, which was less than $0.10 \mathrm{~L} / \mathrm{s} . \mathrm{m}$, and the average permeability coefficient was $0.012-0.014 \mathrm{~m} / \mathrm{d}$, which was less than $10^{-4} \mathrm{~cm} / \mathrm{s}$. According to the Regulation of Water Control in China Coal Mine and the Code of Engineering Geology Investigation Technology in China (Tab. 5), the overburden strata of the working face S2II313 goaf demonstrated weak water abundance and weak-tomicropermeable strata, which indicated that the permeability of goaf overburden strata was poor and had a certain water-resisting ability.

Table 5a Evaluation classification of the permeability of overburden strata

\begin{tabular}{|l|c|c|}
\hline \multicolumn{1}{|c|}{ Type } & $K / \mathrm{m} / \mathrm{s}$ & $\begin{array}{c}\text { Failure characteristics of } \\
\text { overburden strata }\end{array}$ \\
\hline Extremely strong permeability & $>1$ & Caving cracking \\
\hline Strong permeability & $10^{-1}-1$ & Severe cracking \\
\hline Medium permeability & $10^{-4}-10^{-1}$ & General cracking \\
\hline Weak permeability & $10^{-7}-10^{-4}$ & Microcracking \\
\hline
\end{tabular}

Table $5 \mathbf{b}$ Evaluation classification of the water abundance of overburden strata

Table $\mathbf{5} \mathbf{b}$ Evaluation classification of the water abundance of overburden strata
\begin{tabular}{|l|c|}
\hline \multicolumn{1}{|c|}{ Type } & $q / \mathrm{L} / \mathrm{s} . \mathrm{m}$ \\
\hline Extremely strong water abundance & $>5$ \\
\hline Strong water abundance & $1-5$ \\
\hline Medium water abundance & $0,1-1$ \\
\hline Weak water abundance & $<0,1$ \\
\hline
\end{tabular}

For the packer test in No. 1 hole, the $q$ was $0.133 \mathrm{~L} / \mathrm{s} . \mathrm{m}$, which was larger than $0.10 \mathrm{~L} / \mathrm{s} . \mathrm{m}$, and the average permeability coefficient was $0.26 \mathrm{~m} / \mathrm{d}$, which was larger than $10^{-4} \mathrm{~cm} / \mathrm{s}$. According to the regulation and code in China (Tab. 5), the goaf overburden strata of working face III3142 demonstrated medium water abundance and permeable strata, thus indicating that the goaf overburden strata had excellent permeability. Therefore, the goaf water can easily permeate into working face III3142 along the overburden strata fractured zone between the two working faces.

\section{CONCLUSIONS}

In order to estimate the compaction degree of goaf overburden strata, the integrity and permeability of the goaf overburden strata were studied by using the RQD index, field packer test method, and borehole television exploration. The permeability coefficient and RQD of goaf overburden strata were obtained, and the two goafs compaction were estimated. The following conclusions could be drawn:
(1) The overburden strata permeability of the boundary goafs of two adjacent coal mines is measured by the packer test, and the permeability of the two goaf overburden strata is different. The permeability of the goaf overburden strata of the production coal mine is better than that of the abandoned coal mine. The compaction of the abandoned coal mine goaf is better than that of the production mine.

(2) The borehole television is an effective method for exploring the overburden strata integrity of coal mine goafs That is, the fracture development can be clearly observed.

(3) The production of the Yuanzhuang coal mine remains unaffected by the goaf water in the Shengzhuang coal mine, thus indicating that the goaf overburden strata of the Shenzhuang mine is well compacted and has a certain water-resisting ability.

(4) The production practice is consistent with the test results. The permeability measurement using the packer test can be used to indirectly evaluate the compaction of the goaf overburden strata. The research results can provide a reference for the water inrush risk evaluation of goaf water in abandoned coal mines.

In this study, integrity and permeability are used to evaluate the goaf overburden strata compaction. The method is simple, the evaluation index is less, and it is easy to obtain. It provides a method for evaluating the compaction of goaf and lays a foundation for preventing goaf water hazards from adjacent abandoned coal mines. However, the compaction degree and the water-resisting ability in goaf are also closely related to the composition of fillings in goaf and the change of physical properties after water encounter. Therefore, the properties of the fillings in goaf after the goaf water level recovery should be considered in future studies, which can provide a basis for the prevention and control of water hazards in abandoned mines.

\section{Acknowledgements}

The study was supported by the National Natural Science Foundation of China (Grant No. 41272278), the Key Projects of the Natural Science Foundation in Universities of Anhui (Grant No. KJ2017A073), and the Research Foundation for Young Teachers of Anhui University of Science and Technology (Grant No. QN201612).

\section{REFERENCES}

[1] Zhang, P. S., Yan, W., Zhang, W. Q., Yang, W. Y., \& An, Y. F. (2018). Study on factors influencing groundwater inrush induced by backstopping of a coal seam with a hidden fault. Journal of Mining \& Safety Engineering, (China), 35(4), 765-772.

[2] Zhang, R., Jiang, Z. Q., Zhou, H. Y., Yang, C. W., \& Xiao, S. J. (2014). Groundwater outbursts from faults above a confined aquifer in the coal mining. Nature Hazards, 71(3), 1861-1872. https://doi.org/10.1007/s11069-013-0981-7

[3] Zhou, M. R., Hu, F., Yan, P. C., \& Wang, Y. (2018). Laser induced fluorescence spectrum analysis of water inrush in coal mine based on FCM. Spectroscopy and Spectral Analysis, 38(5), 1572-1576.

[4] Wu, Q. (2014). Progress, problems and prospects of prevention and control technology of mine water and reutilization in China. Journal of China Coal Society, (China), 39(5), 795-805. 
[5] Gui, H. R., Qiu, H. L., Qiu, W. Z., Tong, S. J., \& Zhang, H. Z. (2018). Overview of goaf water hazards in China coalmines. Arabian Journal of Geosciences, 11(3), 2-10. https://doi.org/10.1007/s12517-018-3391-z

[6] Gui, H. R. \& Lin, M. L. (2017).Patterns of gob-water inrush in Chinese coalmines. Water Practice and Technology, 12(2), 444-452. https://doi.org/10.2166/wpt.2017.047

[7] Wu, Q. \& Zhou, W. F. (2008). Prediction of groundwater inrush into coal mines from aquifers underlying the coal seams in China: vulnerability index method and its construction. Environmental Geology, 56(2), 245-254. https://doi.org/10.1007/s00254-007-1160-5

[8] Tu, S. H., Zhang, C., Yang, G. Y., Bai, Q. S., \& Yan, R. L. (2016). Research on permeability evolution law of goaf and pressure-relief effect. Journal of Mining \& Safety Engineering, (China), 33(4), 571-577.

[9] Meng, Z. P., Shi, X. C., \& Li, G. Q. (2016). Deformation failure and permeability of coal-bearing strata during longwall mining. Engineering Geology, 208, 69-80. https://doi.org/10.1016/j.enggeo.2016.04.029

[10] Hu, G. Z., Xu, J. L., Ren, T., Gu, C. X., Qin, W., \& Wang, Z. W. (2018). Adjacent seam pressure-relief gas drainage technique based on ground movement for initial mining phase of longwall face. International Journal of Rock Mechanics and Sciences, 77, 237-245. https://doi.org/10.1016/j.jijmms.2015.04.009

[11] Yihdego, Y. \& Paffard, A. (2017). Predicting open pit mine inflow and recovery depth in Druvuljin soum, Zavkhan Province, Mongolia. Mine Water and the Environment, 36(1), 114-123. https://doi.org/10.1007/s10230-016-0419-z

[12] Adams, R. (2014). A review of mine water rebound predictions from the VSS-Net model. Mine Water and the Environment, 33(4), 114-123. https://doi.org/10.1007/s10230-014-0312-6

[13] Banks, D., Frolik, A., Gzyl, G., \& Rogoz, M. (2018). Modeling and monitoring of mine water rebound in an abandoned coal mine complex: Siersza Mine, Upper Silesian Coal Basin, Poland. Hydrogeology Journal, 18(2), 519-534. https://doi.org/10.1007/s10040-009-0534-z

[14] Kim, S. M. \& Choi, Y. (2018). A simplified model-based program for the analysis and visualization of groundwater rebound in abandoned mines to prevent contamination of water and soils by acid mine drainage. International Journal of Environmental Research and Public Health, 951, 1-19. https://doi.org/10.3390/ijerph15050951

[15] Zhang, G. C., Liang, S. J., \& Tan, Y. L. (2018). Numerical modeling for longwall pillar design: a case study from a typical longwall panel in China. Journal of Geophysics and Engineering, 15(1), 121-134. https://doi.org/10.1088/1742-2140/aa9ca4

[16] Brett, A. P., Deepak, A., \& Hua, G. (2018). Simulating mining-induced strata permeability changes. Engineering Geology, 237, 208-216. https://doi.org/10.1016/j.enggeo.2018.03.001

[17] Bai, Q. S., Tu, S. H., Yuan, Y., \& Wang, F. T. (2013). Back analysis of mining induced response on the basis of goaf compaction theory. Journal of China University of Mining \& Technology, (China), 4(3), 355-361.

[18] Meng, Z. P., Zhang, J., Shi, X. C., Tian, Y. D., \& Li, C. (2016). Calculation model of rock mass permeability in coal mine goaf and its numerical simulation analysis. Journal of China Coal Society, (China), 41(8), 1997-2005.

[19] Adhikary, D. P. \& Guo, H. (2015). Modeling of longwall mining-induced strata permeability change. Rock Mechanics and Rock Engineering, 48, 345-359. https://doi.org/10.1007/s00603-014-0551-7

[20] Schatzel, S. J., Karacan, C. O., Dougherty, H., \& Gerrit, V. R. (2012). An analysis of reservoir conditions and responses in longwall panel overburden during mining and its effect on gob gas well performance. Engineering Geology, 127, 65-74. https://doi.org/10.1016/j.enggeo.2012.01.002

[21] Qureshi, M. U., Khan, K. M., Bessaih, N., Khalid, A. M., \& Khaloud, A. S. (2014). An empirical relationship between insitu permeability and RQD of discontinuous sedimentary rocks. Electronic Journal of Geotechnical Engineering, 19(R), 4781-4790.

[22] Song, K., Yan, E. C., \& Chen, G. (2014). Hydraulic conductivity estimation of rock mass in water sealed underground storage caverns. Chinese Journal of Rock Mechanics and Engineering, (China), 33(3), 575-580.

[23] Vincenzo, P., Antonella, B., Francescal, E. A., Biler, A. R., Ceyhan, A. H., Disli, E., Kahraman, S., \& Taskm, M. (2018). Estimation of rock mass permeability using variation in hydraulic conductivity with depth: experiences in hard rocks of western Turkey. Bulletin of Engineering Geology and the Environment, 77, 1663-1671. https://doi.org/10.1007/s10064-017-1058-8

[24] Xue, D. J., Zhou, H. W., Kong, L., Zhao, T., Yi, H. Y., \& Tang, X. L. (2012). Mechanism of unloading-induced permeability increment of protected coal seam undermining. Chinese Journal of Geotechnical Engineering, 34(10), 19101916.

[25] Lu, Y. L., \& Wang, L. G. (2015). Numerical simulation of mining-induced fracture evolution and water flow in coal seam floor above a confined aquifer. Computers and Geodetics, 67, 157-171. https://doi.org/10.1016/j.compgeo.2015.03.007

[26] Khanal, M., Guo, H., \& Adhikary, D. P. (2018). 3D numerical study of underground coal mining induced strata deformation and subsequent permeability change. Geotechnical and Geological Engineering, 1, 1-15.

[27] Holla, L. \& Buizen, M. (1990). Strata movement due to shallow longwall mining and the effect on ground permeability. AusIMM Proceedings, 295(1), 11-18.

[28] Guo, H. L., Yuan, L., Shen, B. T., Qu, Q. D., \& Xue, J. H. (2012). Mining-induced strata stress changes, fractures and gas flow dynamics in multi-seam longwall mining. International Journal of Rock Mechanics and Mining Sciences, 54,129-139. https://doi.org/10.1016/j.jijmms.2012.05.023

[29] Zhang, C. L., Yu, L., Feng, R. M., Zhang, Y., \& Zhang, G. J. (2018). A numerical study of stress distribution and fracture development above a protective coal seam in longwall mining. Processes, 6(9), 1-20. https://doi.org/10.3390/pr6090146

[30] Chen, Y. D., Selvadurai, A. P., \& Liang, W. G. (2018). Computational modeling of groundwater inflow during a longwall coal mining advance: a case study from the Shanxi Province, China. Rock Mechanics and Rock Engineering, 6(9), 1-20.

[31] Song, K., Yan, E. C., \& Xie, L. F. (2013). The characterization of deep rock joints from Borehole Television image, London: Taylor and Francis Group, 81-86. https://doi.org/10.1201/b14917-13

[32] Cardenas, M. B. \& Zlotnik, V. A. (2003). A simple constanthead injection test for streambed hydraulic conductivity estimation. Groundwater, 41(6), 867-871. https://doi.org/10.1111/j.1745-6584.2003.tb02428.x

[33] Deere, D. U. (1964). Technical description of rock cores for engineering purposes. Rock Mechanics and Engineering Geology, 1, 16-22.

[34] Vavro, M., Soucek, K., \& Stas, L. (2015). Application of alternative methods for determination of rock quality designation (RQD) index: a case study from the Rozna luranium mine, Strazek Moldanubicum, Bohemian Massif, Czech Republic. Canadian Geotechnical Journal, 52(10), 1466-1476. https://doi.org/10.1139/cgj-2014-0377

[35] Kumar, R. J., Choudhury, D., \& Bhargava, K. (2016). Determination of blast-induced ground vibration equations for rocks using mechanical and geological properties. 
Journal of Rock Mechanics and Geotechnical Engineering,

36(8), 341-349. https://doi.org/10.1016/j.jrmge.2015.10.009

\section{Contact information:}

Xiaorong ZHAl, Lecturer

(Corresponding author)

1) School of Earth and Environment,

Anhui University of Science and Technology,

2) Key Laboratory of Mine Geological Disaster Prevention and Environment

Protection of Anhui Higher Education Institutes,

Room 312, No. 168 Taifeng Road,

Tianjiaan district, Huainan, Anhui Province, China

E-mail: zhaixiaorong@sina.com

Guangtao WANG, PhD candidate

School of Earth and Environment,

Anhui University of Science and Technology, China

Room 108, No. 168 Taifeng Road,

Tianjiaan district, Huainan, Anhui Province, China

E-mail: 1830624237@qq.com

Jiwen WU, Full Professor

School of Earth and Environment,

Anhui University of Science and Technology,

Room 314, No. 168 Taifeng Road

Tianjiaan district, Huainan, Anhui Province, China

E-mail: jwwuaust@163.com

Yaoshan BI, PhD candidate

School of Earth and Environment,

Anhui University of Science and Technology,

Room 107, No. 168 Taifeng Road,

Tianjiaan district, Huainan, Anhui Province, China

E-mail:962594240@qq.com 